\title{
EDUCAÇÃO JURÍDICA PARA ALÉM DA DOGMÁTICA: UM ESTUDO DE CASO
}

\author{
A PARTIR DA PERSPECTIVA HUMANISTA DE NUSSBAUM ${ }^{1}$
}

\section{LEGAL EDUCATION BEYOND DOGMATISM: A CASE STUDY BASED ON NUSSBAUM HUMANIST PERSPECTIVE}

\section{Resumo}

${ }^{2}$ Carlos Eduardo Paletta Guedes

${ }^{4}$ Marcos Vinício Chein Feres

Este artigo parte de uma análise crítica da educação jurídica brasileira, voltada para a linguagem oficial e pouco reflexiva. Tentativas de inovação, portanto, merecem ser pesquisadas. A disciplina "Instituições de Direito", da UFJF, com métodos pedagógicos inovadores, incluindo filmes e plataforma online, foi o foco da pesquisa. Utilizando o conceito de "cultivo da humanidade" de Martha Nussbaum, realizou-se uma pesquisa empírico-qualitativa dos filmes trabalhados em aula e textos produzidos pelos estudantes, a fim de verificar se aquele método desenvolvia as capacidades elencadas por Nussbaum. A análise qualitativa indica que as inovações tem se mostrado eficazes ao desenvolver essas capacidades.

Palavras-chave: Educação Jurídica; Capacidades; Filme; Inovação.

\begin{abstract}
This article begins with a critical account of Brazilian legal education, devoted to official language and lack of reflexiveness. Any attempt to innovate deserves to be researched. The focus of the study is the discipline "Legal Institutions" taught at the UFJF, which adopts innovative pedagogical methods, especially movies and online platform. Using Martha Nussbaum concept of "cultivating humanity", empirical-qualitative research was implemented, investigating if this method developed in the students the capacities Nussbaum describes. The data and the qualitative analysis indicate that those innovations have been successful in developing those capacities.
\end{abstract}

Key words: Legal Education; Capacities; Movies; Innovation.

\footnotetext{
${ }^{1}$ Este Artigo Tem o Apoio Financeiro Do CNPq e da FAPEMIG.

${ }^{2}$ Mestrando em Direito e Inovação pela Universidade Federal de Juiz de Fora, UFJF - MG, (Brasil). Professor da Faculdade de Direito Vianna Junior - MG, (Brasil). E-mail: cepguedes@ yahoo.com.br

${ }^{4}$ Bolsista de Produtividade PQ-2/CNPq. Doutor em Direito pela Universidade Federal de Minas Gerais, UFMG - MG, (Brasil). Professor Associado da Universidade Federal de Juiz de Fora, UFJF - MG,(Brasil). E-mail: mvchein@gmail.com
} 


\section{INTRODUÇÃ̃O}

Diz a mitologia grega que a Hidra de Lerna possuía corpo de dragão e três cabeças. Tal como ela, a educação jurídica brasileira divide-se em três "cabeças" ou eixos, conforme o Conselho Nacional de Educação (Resolução CNE/CES no 9 de 2004): Eixos de Formação Fundamental, Formação Profissional e Formação Prática.

Ao detalhar a composição de cada um desses eixos (artigo $5^{\circ}$ da citada Resolução), constata-se que o primeiro tem como objetivo a integração do estudante, estabelecendo as relações do Direito com outras áreas do saber, tais como Antropologia, Ciência Política, Economia, Ética, Filosofia, História, Psicologia e Sociologia. Já o segundo eixo abrange o enfoque dogmático e conhecimento dos diversos ramos do Direito, sendo citados como necessários os conteúdos essenciais sobre Direito Constitucional, Direito Administrativo, Direito Tributário, Direito Penal, Direito Civil, Direito Empresarial, Direito do Trabalho, Direito Internacional e Direito Processual. Finalmente, com a Formação Prática, objetiva-se a integração entre prática e os conteúdos teóricos desenvolvidos nos demais Eixos. Aqui são citados o Estágio Curricular Supervisionado, Trabalho de Curso e Atividades Complementares.

Antes desse detalhamento, os artigos $3^{\circ}$ e $4^{\circ}$ da Resolução mencionada fornecem exigências mais gerais para a formação do graduando em Direito. Assim é que o artigo $3^{\circ}$ estabelece que se deverá assegurar uma formação geral, humanística e axiológica, capacidade de análise, domínio de conceitos e da terminologia jurídica, além de adequada argumentação, interpretação e valorização dos fenômenos jurídicos e sociais, tudo isso somado a uma postura reflexiva e uma visão crítica indispensável ao exercício da Ciência do Direito, da prestação da justiça e do desenvolvimento da cidadania. Reforçando esses aspectos, diz o artigo $4^{\circ}$ :

\footnotetext{
Art. $4^{\circ}$. O curso de graduação em Direito deverá possibilitar a formação profissional que revele, pelo menos, as seguintes habilidades e competências:

I - leitura, compreensão e elaboração de textos, atos e documentos jurídicos ou normativos, com a devida utilização das normas técnico-jurídicas;

II - interpretação e aplicação do Direito;

III - pesquisa e utilização da legislação, da jurisprudência, da doutrina e de outras fontes do Direito;

IV - adequada atuação técnico-jurídica, em diferentes instâncias, administrativas ou judiciais, com a devida utilização de processos, atos e procedimentos;

V - correta utilização da terminologia jurídica ou da Ciência do Direito;

VI - utilização de raciocínio jurídico, de argumentação, de persuasão e de reflexão crítica;

VII - julgamento e tomada de decisões; e,

VIII - domínio de tecnologias e métodos para permanente compreensão e aplicação do Direito.
} 
Nota-se aí uma consonância com o disposto na própria Constituição Federal de 1988, cujo texto estabelece que a educação visa "ao pleno desenvolvimento da pessoa, seu preparo para o exercício da cidadania e sua qualificação para o trabalho" (artigo 205). Mais uma vez, três "cabeças", não necessariamente as mesmas, mas que podem ser identificadas no corpo das exigências para o ensino jurídico.

O presente trabalho parte desse pano de fundo institucional para discutir a educação jurídica para além da dogmática, o Eixo que historicamente domina o ensino da Ciência Jurídica. Wander Bastos (1997, p. 37) já observara com pertinência que “os currículos jurídicos estudam a linguagem oficial do Estado e este foi o problema central da nossa história curricular: transmitir e reproduzir o conhecimento oficial". Este "aprendizado dos códigos", da "fala oficial do Estado", deve, como se viu acima, abrir-se para absorver outros padrões de educação que permitam ao estudante de Direito conviver com o conhecimento social interdisciplinar ou a "fala crítica e avaliativa do Estado" (BASTOS, 1997, p. 37).

A Hidra do ensino jurídico, se assim pode ser chamada, tem uma cabeça (a dogmática) maior que as outras e que, pelo seu tamanho superior, acaba influenciando as duas menores. Mas que fique claro: não se defende, com este trabalho, a decapitação da cabeça dogmática da Hidra, até porque, como reza a lenda, duas cabeças nascem depois daquela decapitada. Há, ao contrário, apenas o reconhecimento da necessidade de evolução dos métodos de ensino na Faculdade de Direito para que, afinal, se cumpram os ditames reflexivos, argumentativos e axiológicos da Resolução nº 9/2004, passados já mais de dez anos.

A questão não é nova e perpassa os debates sobre o currículo jurídico desde Rui Barbosa, que, em 1878, quis inserir a Sociologia no Curso de Direito (BASTOS, 1997, p. 39), fato que só se concretizou em 1972. Foi San Tiago Dantas, porém, na primeira metade do século passado, quem chamou atenção para uma questão até então não abordada no país: o método da reflexão jurídica, seu aprendizado e desenvolvimento. (BASTOS, 1997, p. 47-48)

Incrivelmente, os mesmos problemas persistem ainda hoje, mesmo sob os ditames de uma regulação, se comparadas com as anteriores, aberta, dialógica, plural. É como se o mesmo dogmatismo de conteúdo avançasse para o método do ensino jurídico, dogmatizando a própria a aula do Curso de Direito. 
Tudo isso se dá num contexto de expansão quantitativa do acesso à educação superior jurídica. De acordo com dados extraídos do Portal do Ministério da Educação (E-Mec), no Brasil existem hoje 918 faculdades de Direito autorizadas, número expressivo se comparado, por exemplo, com os Estados Unidos, que possui, de acordo com o sítio da American Bar Association, 205 faculdades de Direito ${ }^{6}$. Comparando-se a população dos dois países aproximadamente 206 milhões no Brasil e 324 milhões nos Estados Unidos, percebe-se a amplitude dessa diferença ${ }^{7}$.

Mais recentemente, Roberto Mangabeira Unger elaborou uma crítica ao quadro atual do ensino jurídico, propondo, sem seguida, uma "nova faculdade de Direito no Brasil" (UNGER, 2016, p. 113). Segundo o professor de Harvard, o ensino atual do direito no Brasil malogrou e um de seus motivos principais está no conteúdo e no método das aulas.

\begin{abstract}
Mas o que faz o professor na aula é pronunciar uma conferência, repleta de tecnicismos, cuja arbitrariedade é mal disfarçada pela sua antiguidade. Não é nem teoria nem prática. Comumente, é apenas a repetição de fórmulas doutrinárias de pouca ou nenhuma utilidade: as três maneiras de interpretar a norma tal, as duas escolas de pensamento sobre o instituto jurídico qual e assim por diante, numa procissão infindável de preciosismos que não podem ser lembrados (apenas efemeramente decorados) porque não podem ser, em qualquer sentido, praticados. (UNGER, 2016, p.115)
\end{abstract}

Após analisar o que chama de antigo e o novo formalismos (o primeiro, simples exposição do direito positivo tal como construído por legisladores e juízes; o segundo, submetendo as normas a análises de valores e interesses, mas ainda sem questionar as instituições), ele segue dizendo que a cultura jurídica nacional estaria entre estes dois polos, distante, pois, tanto de um pensamento verdadeiramente teórico quanto de uma utilidade profissional imediata (UNGER, 2016, p. 115). O problema, segundo Unger, é a fixação numa abordagem enciclopédica, exegética e escolástica do direito vigente, mas que, ao final, acaba por se tornar um artefato autorreferente que possui consequências práticas.

O problema é que, nesse contexto, advogados e juristas brasileiros tem perdido cada vez mais relevância no cenário do debate nacional, cedendo lugar, principalmente, para os economistas (UNGER, 2016, p. 118).

\footnotetext{
${ }^{6}$ Número considerado excessivo em debates públicos sobre o tema nos Estados Unidos. Ver, por exemplo, o artigo de Peter Cohan, "Does America need 202 law schools?".

7 Poder-se-ia argumentar que o curso de Direito, no Brasil, cumpre muitas vezes o papel de formar bacharéis para variadas atividades profissionais, tal como o "undergraduate" norte-americano, o que explicaria a diferença. Contudo, isso não afasta o problema do número elevado de faculdades de Direito no Brasil e a dificuldade de se garantir um ensino jurídico de qualidade.
} 
Diante desse quadro de predominância, nos cursos jurídicos, de uma "mentalidade conservadora, disciplinar e descritiva do ordenamento jurídico oficial” (ADEODATO, 1997, p. 149), deve merecer destaque justamente aquilo que quebra os paradigmas formalistas: as práticas inovadoras dentro da sala de aula, ainda que individuais e isoladas. Se, no momento, não se pode crer num modelo de faculdade de Direito que supere os formalismos, deve-se buscar as práticas inovadoras que possam, se expandidas, combinar os dois anseios de Unger.

Considerando o domínio do dogmatismo na educação jurídica, é fundamental que qualquer tentativa de inovação mereça um olhar atento de pesquisadores. E qualquer pesquisa empírica deve ter por base um marco teórico que estabeleça os parâmetros que balizarão o entendimento dos dados. Coloca-se, então, uma questão: quais devem ser os princípios norteadores desse novo paradigma da educação jurídica? Como imaginar uma pedagogia universitária que cumpra o papel acima descrito, que vá além da educação puramente técnica ou vocacional que parece ser a essência do ensino jurídico no Brasil?

A partir do cultivo da humanidade, exposto por Nussbaum (2003), pode-se afirmar que é possível, do ponto de vista fático e estrutural, romper-se com o excessivo dogmatismo na educação jurídica por meio de iniciativas pedagógicas que valorizem o trabalho em grupo, o raciocínio crítico e autônomo e a reflexão sobre os problemas sociais e econômicos brasileiros.

A metodologia de pesquisa aqui adotada consiste numa abordagem empíricoqualitativa em que se pretende analisar um modelo de aula de Direito por meio de coleta de dados documentais diretos referentes ao trabalho de estudantes de Direito e de outras áreas afins imersos em um regime didático-pedagógico o qual pretende possibilitar novas formas de pensar e de refletir sobre o Direito como instituição. Nesse contexto, esta pesquisa tem por meta a análise da disciplina do primeiro período do Curso de Direito lecionada na Faculdade de Direito da Universidade Federal de Juiz Fora, a saber, Instituições de Direito. No entanto, é necessário apontar que a disciplina não se restringe a alunos do curso de Direito, sendo, pois, disponibilizada para estudantes de outras áreas do saber, o que revela sua propensão para a real convivência com a interdisciplinaridade.

Assim sendo, este artigo divide-se em três partes. A primeira consiste numa apresentação sobre o referencial teórico e a metodologia utilizada. A segunda se refere à 
Carlos Eduardo Paletta Guedes \& Marcos Vinício Chein Feres

análise de dados e à discussão dos resultados. Por fim, conclui-se no sentido de apontar rumos para uma proposta de educação jurídica inovadora.

\section{REFERENCIAL TEÓRICO E ESTRATÉGIAS METODOLÓGICAS.}

A presente pesquisa tem como foco a disciplina de $1^{\circ}$ período "Instituições de Direito", lecionada na Faculdade de Direito da Universidade Federal de Juiz de Fora. Com uma proposta inovadora, incomum no ambiente educativo jurídico, a disciplina trabalha com turmas com alto número de alunos de diferentes cursos, contando o professor, por isso, com o apoio de tutores ou monitores (que são estudantes de períodos mais avançados). A aula, com duração de 3 horas, é dividida da seguinte forma: um filme (documentário ou ficção), seguido de uma atividade em grupos, com apresentação, a cada aula, de um membro selecionado do grupo ( grupos estes fixos que atuarão em conjunto durante todo o semestre letivo), sendo que, somente ao cabo de ambas as atividades mencionadas, caberá ao professor fazer sua exposição do conteúdo. Há, ainda, uma ativa participação dos alunos fora da sala de aula por meio da Plataforma online Moodle, ambiente virtual onde os alunos tomam parte em discussões em fóruns, elaboram textos de forma cooperada (por meio das Wikis) e leem materiais (textos teóricos) e assistem a vídeos.

Para validar a análise desse estudo de caso da disciplina "Instituições de Direito", é essencial se estabelecer o referencial teórico contido na expressão "cultivando a humanidade" de Martha Nussbaum. Em sua defesa do cultivo da humanidade, Nussbaum (2003) afirma que três capacidades são essenciais no mundo atual: em primeiro lugar, a capacidade de exame crítico de si mesmo e de sua tradição - ou, em termos socráticos, deve-se viver uma vida examinada em que se é capaz de dar e cobrar argumentos, sem aceitar passivamente conhecimentos tradicionais ou convencionais (NUSSBAUM, 2003, p. 9). Contrapondo a educação defendida por Aristófanes, que desencorajava o questionamento das tradições, Nussbaum (2003, p. 15) retoma Sócrates que não reconhecia autoridade a não ser a da razão. O antigo debate entre Sócrates e seus adversários possui valor ainda hoje: a educação que emancipa é aquela que questiona e critica, que usa o questionamento filosófico não como ferramenta abstrata, mas como parte do dia-a-dia do cidadão.

Nussbaum (2003, p. 27) faz, como se nota, uma defesa veemente da capacidade socrática de examinar, argumentar e questionar, afirmando que disso depende o sucesso da democracia. Esta não deve ser, como já dito, somente um conflito de interesses opostos, mas 
deve comportar deliberações e escolhas sobre o bem comum. É por isso, ela diz, que a educação é tão urgentemente necessária na democracia. A "vida examinada” de Sócrates deve ser uma meta central para a educação na democracia.

A segunda capacidade é aquela de ver-se não somente como um cidadão pertencente ao seu local ou região, mas de ver-se ligado a todos os outros seres humanos por laços de reconhecimento e preocupação (NUSSBAUM, 2003, p. 10). A educação, sob esse enfoque, produziria cidadãos do mundo (kosmou polités), sabedores que estão presos, sim, à localidade de origem, mas também à comunidade humana e suas aspirações e limitações partilhadas.

Retomando as tradições ocidentais greco-romanas sobre cosmopolitismo, Nussbaum (2003, p. 53) considera que essas ideias são recurso essencial para uma cidadania democrática, devendo estar no centro da educação superior. Importante ressaltar a ligação entre a primeira capacidade - o exame socrático - e esta: tornar-se um cidadão do mundo implica estar aberto a duvidar de seu próprio modo de vida e a participar dos intercâmbios de argumentos críticos sobre escolhas éticas e políticas. O estudante-cidadão deve aprender a distinguir aquilo que é paroquial e local daquilo que deve ser recomendado como normativo para outros; aquilo que é arbitrário daquilo que é justificável do ponto de vista argumentativo.

Obviamente, tornar-se um cidadão do mundo não significa abrir mão de suas conexões locais, onde se pode encontrar riqueza existencial. A tarefa do educador é preparar o estudante para fazer de todos os humanos nossos companheiros de cidade. Não se pede a renúncia, como se nota, às afeições especiais e identificações, sejam elas nacionais, étnicas ou religiosas. Deve-se, porém, trabalhar para que qualquer ser humano faça parte de nossa comunidade de diálogo e preocupação. Ser cidadão do mundo requer uma interpretação sensível e empática do outro, transcendendo a inclinação de professores e estudantes de se definirem primariamente em termos de identidades locais.

A terceira capacidade do cidadão, intimamente relacionada com as duas anteriores, de acordo com Nussbaum (2003, p. 10), é a que ela chama de imaginação narrativa, a habilidade de colocar-se no lugar do outro, ser um leitor inteligente da história alheia e compreender as emoções e desejos do outro de uma forma crítica. Segunda a autora, obras de ficção desenvolvem essa capacidade. Nussbaum (2003, p. 90) é uma entusiasta da literatura como ferramenta essencial à preparação para a interação moral e para a formação desses cidadãos livres. A imaginação narrativa, primordialmente formada pela leitura de obras literárias (mas 
Carlos Eduardo Paletta Guedes \& Marcos Vinício Chein Feres possível a partir de filmes, por exemplo ${ }^{8}$ ), contribui para a formação moral na medida em que estimula uma resposta empática às necessidades alheias (através da preocupação com o destino dos personagens), ao mesmo tempo em que demonstra a própria vulnerabilidade do leitor, que pode sofrer tanto quanto aquele personagem. De outro modo, Nussbaum (1995, p. 11-12) deixa claro que sua investigação sobre a imaginação narrativa não pretende ser anticientífica ou substituta de teorias políticas e morais, muito menos colocar as emoções no lugar da argumentação, mas, deve, ao contrário, fornecer elementos e insights para a construção de uma teoria político-moral adequada, além de desenvolver capacidades morais sem as quais os cidadãos não conseguirão transformar em realidade as conclusões normativas de quaisquer teorias.

O certo é que, pela imaginação narrativa de Nussbaum, há relevância moral na criação artística, no potencial de imaginar a situação alheia em toda a sua complexidade e profundidade, que não pode ser descartada por uma estreiteza dogmática. E se se pensa no papel da educação na formação jurídica, mais importante ainda é o papel de uma visão enriquecida por experiências literárias, fílmicas ou artísticas, que podem, inclusive, ir além do texto. Sobre esse último ponto, Maksymilian Del Mar (2010) descreve como o operador do Direito desenvolve tendências de limitar seu olhar para o problema jurídico, devendo ser introduzidas a arte e a criação de trabalhos imaginativos para aprimorar a capacidade do estudante de Direito para aprender a olhar sob novos ângulos. Segundo Del Mar (2010), o ensino de ética nos cursos jurídicos não pode se prender exclusivamente ao que ele chama de profissionalismo, vinculado ao textual, às legislações substantivas e procedimentais. É vital, diz o autor, que a educação ética não se restrinja unicamente às fontes textuais. "Por que o profissionalismo não é o bastante?”, se pergunta Del Mar (2010, p. 957), ao que ele responde que limitar o lugar da educação ética à finalidade e à identidade profissionais é colocar em risco o desenvolvimento da sensibilidade moral dos estudantes de Direito pela redução à seguinte ideia: o estudante pensará que, por agir como profissional, ele estará agindo eticamente, quer dizer, haveria uma subsunção da ideia ética ao profissionalismo, não o inverso (DEL MAR, 2010, p. 975).

\footnotetext{
${ }^{8}$ Nussbaum, especialmente em sua obra Poetic Justice, dá preferência à literatura, mas vê os filmes também como possíveis ferramentas para o estímulo da imaginação narrativa $(1995$, p. 6).
} 
Importante, ainda, salientar que Del Mar (2010, p. 973), na linha de Nussbaum, tampouco acredita que a educação estética deva substituir o ensino de leis e princípios, obviamente defendendo que as duas atividades sejam complementares.

Não se deve pensar que essa imersão imaginativa deva se reduzir ao desenvolvimento da capacidade empática. As três capacidades de Nussbaum se inter-relacionam, de forma que, para além da humanização e individualização potencializadas pela arte, deve-se estimular uma leitura crítica, plural, indagadora, aberta a variadas perspectivas, o que nos faz retomar a primeira capacidade, a do exame socrático. Enfim, as três capacidades se somam para que a academia se torne um ambiente crítico, cativante e criativo, não excludente, sectário ou interditado.

Dessa forma, tomando por base o referencial teórico supra, o presente artigo restringe as perguntas introdutórias acima à seguinte questão: a disciplina "Instituições de "Direito" (UFJF), com suas inovações pedagógicas, desenvolve nos educandos as capacidades elencadas por Nussbaum, no sentido de apresentar uma proposta para uma possível educação jurídica crítica e reflexiva?

A fim de testar a hipótese de que o método de ensino adotado na disciplina “Instituições de Direito" confere ao estudante o pleno desenvolvimento preconizado no texto constitucional, foi utilizado o método empírico (EPSTEIN, KING, 2002) na modalidade eminentemente qualitativa. Como se pretende analisar essa disciplina específica que já vem sendo lecionada na Universidade Federal de Juiz de Fora, foram coletados dados a partir de documentos institucionais e da Plataforma Moodle (referente ao primeiro semestre de 2016), que é a ferramenta principal de comunicação entre os alunos, divididos em grupos, monitores (também estudantes, mas de períodos mais avançados) e o professor da disciplina. Por meio de indicadores voltados para as três capacidades apontadas por Nussbaum, buscou-se verificar se o método de ensino não tradicional cumpriu sua pretensão de desenvolver plenamente o estudante e preparou-o para o exercício da cidadania (conforme texto Constitucional citado acima) - ou seja, nos moldes de Epstein e King (2002, p. 62), se a teoria de Nussbaum estiver correta, aquelas três competências, se desenvolvidas na sala de aula, contribuirão para o desenvolvimento da cidadania, não somente para uma carreira especializada (NUSSBAUM, 2003, p. 294). 
Carlos Eduardo Paletta Guedes \& Marcos Vinício Chein Feres

Quanto à primeira capacidade, o indicador escolhido foi a participação nos fóruns da plataforma Moodle, um ambiente privilegiado para a troca de argumentos e tomada de posição dos estudantes. Foram avaliados os seguintes aspectos: número de respostas por aluno a cada questão colocada; troca de argumentos entre alunos ou entre aluno e instrutor.

Para a segunda capacidade - reconhecimento do outro - foram avaliados os títulos de filmes utilizados na sala de aula, seu local de produção e temática. Com isso, pretendeu-se analisar o grau de abertura a linguagens e realidades diferentes daquela com a qual o estudante convive em seu dia-a-dia. A participação em Wikis também será considerada como reconhecimento do outro na elaboração conjunta de textos relacionados à matéria.

Por fim, no que diz respeito à terceira capacidade, foram avaliados os filmes de ficção e as manifestações em postagens dos alunos na Plataforma Moodle, relacionando o conteúdo narrativo e a disciplina.

\section{DISCUSSÃO DE RESULTADOS}

No primeiro semestre de 2016, a disciplina em análise foi lecionada para três turmas, que serão identificadas aqui como Turmas A, M e N (conforme titulação constante da própria Plataforma Moodle). A Turma A foi dividida em 10 grupos sob responsabilidade de cinco instrutores. A Turma $\mathrm{N}$ foi dividida em 12 grupos com quatro instrutores. E finalmente a Turma M foi dividida em 10 grupos com 4 instrutores.

Nota-se, nos fóruns, que as indagações formuladas pelo professor pretendem estimular os debates. Assim, por amostragem, tome-se como exemplo a seguinte pergunta no primeiro fórum do semestre: "Procurem discutir, a partir dos conceitos de norma, ordem institucional e ordem normativa, a relação entre democracia e impeachment. Como deve ser analisada a lei 1079/50 na realidade contemporânea brasileira?”. A pergunta já revela um elemento de contemporaneidade, tendo em vista o momento político vivido no semestre em curso. A mobilização social em torno do tema do "impeachment" é indicativa da necessidade de uma interação do estudante com o seu entorno político, social e econômico.

Em razão dessa contemporaneidade, houve um alto grau de adesão dos estudantes à atividade proposta. As respostas foram variadas, com cada um assumindo sua posição e dando suas justificativas perante os colegas.

Outra pergunta lançada no fórum online, após a aula sobre autonomia moral e direito positivo, foi "Considerando o texto obrigatório da plataforma e o documentário "Cortina de 
fumaça", procurem debater a relação entre autonomia moral e direito positivo, a partir dos seguintes pontos: liberdade versus segurança, escolhas éticas sobre a vida que vale a pena ter e escolhas morais universalizáveis, esfera pública e esfera privada. Qual deve ser a função do direito positivo? Como se constitui a relação entre autonomia privada e autonomia pública?".

Como se nota, a intenção pedagógica é clara: além dos filmes e discussões em sala de aula, os fóruns pretendem cumprir o papel de desenvolver no educando a capacidade de dar e cobrar argumentos, muitas vezes trazendo discussões polêmicas e contemporâneas para a experiência acadêmica do estudante. É bem verdade que, durante a pesquisa, notou-se claramente que os alunos são capazes de dar argumentos, pois respondem com embasamento e propriedade, mas dificilmente cobram de seus colegas algum esclarecimento ou aprofundamento. Nesse aspecto, embora se trate de um fórum, os alunos se importam mais em responder à questão colocada pelo instrutor do que estabelecer, no ambiente virtual, uma conversa entre si. Logo, há aí um ponto que se apresenta vulnerável para se desenvolver a primeira capacidade de Nussbaum: não basta ao educando apresentar sua posição, sem de fato confrontar sua opinião com aquela divergente do colega. Instigar o debate, ligando as pontas soltas dos argumentos dos membros de cada grupo, é um desafio que se coloca, mas que não invalida o uso da ferramenta e o trabalho desenvolvido, visto que, de fato, os alunos e alunas se preocupam em dar suas respostas com justificativas normativas, lógicas, ético-morais ou políticas, muitas vezes antecipando divergências. Todavia, a fragilidade da ferramenta acaba por decorrer do modo pelo qual o estudante é formado ao longo de anos apenas para dar respostas e raríssimas vezes para questionar e cobrar argumentos, o que há de exigir sempre um maior esforço por parte do educador no sentido de incentivar mais questionamentos e menos respostas.

O foco do presente estudo volta-se, agora, para as duas outras capacidades de Nussbaum, intimamente relacionadas como vimos acima: o reconhecimento e a imaginação narrativa. A disciplina analisada tem uma estrutura fixa para as aulas presenciais: a primeira parte é sempre dedicada a um filme (ficção ou documentário) ou episódio de seriado (ficção), seguida de uma atividade em grupo. Finalmente, na parte derradeira da aula, o professor assume o protagonismo e apresenta a matéria com slides projetados, estando sempre aberto a perguntas e comentários dos estudantes. 
Sendo dada tamanha importância aos filmes que, como se destacou, são apresentados em todas as aulas, inclusive no dia da avaliação, é natural que a pesquisa se concentre nessa ferramenta bastante inovadora numa sala de aula em faculdades de Direito, especialmente no presente caso em que um artefato cultural está intrinsicamente ligado ao cotidiano pedagógico de professor e estudantes.

Os filmes apresentados estão listados abaixo:

\begin{tabular}{|c|c|c|c|}
\hline Filme & $\begin{array}{l}\text { Ano e país } \\
\text { de } \\
\text { produção }\end{array}$ & Ficção/documentário & Matéria lecionada \\
\hline $\begin{array}{c}\text { Julgamento de Zé } \\
\text { Bebelo na } \\
\text { minissérie da } \\
\text { Globo (Grande } \\
\text { Sertão Veredas) }\end{array}$ & $\begin{array}{l}\text { 1985, } \\
\text { Brasil }\end{array}$ & $\begin{array}{c}\text { Ficção - } \\
\text { Teledramaturgia }\end{array}$ & $\begin{array}{l}\text { Ordem normativa e ordem } \\
\text { institucional }\end{array}$ \\
\hline $\begin{array}{l}\text { Cortina de } \\
\text { fumaça }\end{array}$ & $\begin{array}{l}2010, \\
\text { Brasil }\end{array}$ & Documentário & $\begin{array}{c}\text { Direito positivo e autonomia } \\
\text { moral }\end{array}$ \\
\hline $\begin{array}{l}\text { Senhor das } \\
\text { Moscas }\end{array}$ & 1990, EUA & $\begin{array}{c}\text { Ficção - } \\
\text { Aventura/Drama }\end{array}$ & $\begin{array}{l}\text { Direito e Estado } \\
\text { Constitucional }\end{array}$ \\
\hline $\begin{array}{l}\text { Pro dia nascer } \\
\text { feliz }\end{array}$ & $\begin{array}{c}2004 / 05, \\
\text { Brasil }\end{array}$ & Documentário & $\begin{array}{l}\text { Direitos humanos e direitos } \\
\text { fundamentais }\end{array}$ \\
\hline Leões e Cordeiros & 2007, EUA & Ficção - Drama & $\begin{array}{l}\text { Repensando o normativo: o } \\
\text { público e o privado }\end{array}$ \\
\hline Quem se importa & $\begin{array}{c}\text { 2013, } \\
\text { Brasil; } \\
\text { EUA; } \\
\text { Tanzânia; } \\
\text { Suíça; } \\
\text { Peru; } \\
\text { Alemanha; } \\
\text { Canadá }\end{array}$ & Documentário & $\begin{array}{c}\text { Direito, Estado e Sociedade } \\
\text { Civil: regulação econômica e } \\
\text { mercado }\end{array}$ \\
\hline $\begin{array}{c}\text { Human - volumes } \\
1,2 \text { e } 3\end{array}$ & $\begin{array}{l}2015, \\
\text { França }\end{array}$ & Documentário & $\begin{array}{c}\text { Vol. } 3 \text { Pessoa } \\
\text { Vol. 1. Direito, Estado e } \\
\text { Sociedade Civil: violência, } \\
\text { criminalidade e políticas } \\
\text { públicas } \\
\text { Vol 2. Revisão }\end{array}$ \\
\hline
\end{tabular}




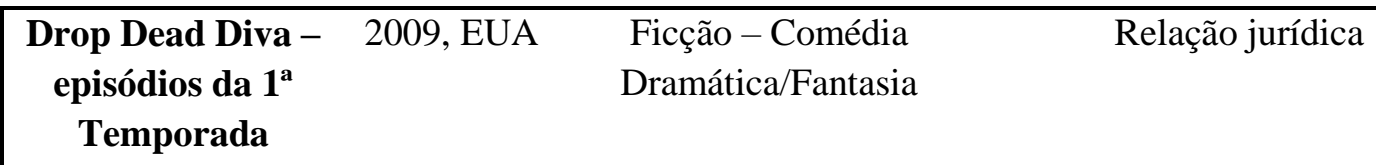

\begin{tabular}{llcc}
\hline Invasões Bárbaras & $\begin{array}{c}\text { França; } \\
\text { Canadá }\end{array}$ & $\begin{array}{c}\text { Ficção - Comédia } \\
\text { dramática }\end{array}$ & Direito e valores: justiça \\
&
\end{tabular}

A escolha dos filmes já indica uma variedade temática importante, com diferentes visões de mundo. Há filmes, seriados de ficção e documentários. Quanto aos países de produção, há produção de oito países diferentes. Esse número que, à primeira vista, poderia parecer reduzido (e, portanto, limitador da segunda capacidade de Nussbaum que preconiza um reconhecimento de realidades distantes e diferentes), merece uma análise mais detalhada. Nussbaum diz que o reconhecimento não se liga unicamente ao outro distante geograficamente, mas àquele que, muitas vezes, mesmo vivendo em nossas comunidades, não conta com a devida estima social. Por isso, a escolha de filmes brasileiros não limita, mas pode mesmo expandir, o reconhecimento de que trata a citada autora. Quanto aos filmes estrangeiros, merece destaque as temáticas tratadas e o fato de que estão representados os continentes europeu, africano e americano (norte e sul). Logo, considerando essa amplitude, as turmas são expostas a diferentes visões de mundo, discursos e expressões valorativas e estéticas.

Se até agora foi tratada a questão do reconhecimento nos filmes, há que se analisar mais detidamente a terceira capacidade, a imaginação narrativa. Para tal análise, há que se concentrar nos filmes/seriados de ficção e qual seu impacto nos estudantes, mais especificamente relacionando a mídia ao conteúdo da disciplina.

No episódio de teledramaturgia "Grande Sertão: Veredas", baseado na obra de Guimarães Rosa, ocorre o julgamento de Zé Bebelo. Os estudantes assistiram na sala de aula a este vídeo e depois criaram, em grupos, textos colaborativos (Wiki) na Plataforma online Moddle, relacionado o tema da aula (ordem normativa e ordem institucional) com as aspectos dramáticos da mídia. A atividade proposta foi: "Considerando as discussões travadas no fórum, construam um texto coletivo contendo uma análise crítica da ordem institucional e normativa brasileira contemporânea, a partir da leitura obrigatória da plataforma e do exemplo da literatura brasileira em Grande Sertão: veredas". 
O texto colaborativo, por si só, já demonstra aspectos de reconhecimento do outro (segunda capacidade) e argumentação (primeira capacidade), visto que se deve respeitar o texto alheio ao mesmo tempo em que se deve argumentar textualmente considerando seus pontos de vista divergentes, o que leva ao questionar a si mesmo e rever, se for o caso, seus próprios argumentos. Mas, deixando as duas primeiras capacidades de lado, é de se notar que a condição dos personagens fictícios, a dramatização do julgamento, seus diálogos e resultado, foram valiosos para o desenvolvimento da terceira capacidade.

O grupo 2 da Turma M, por exemplo, coloca claramente de que forma a participação de um personagem específico contribuiu pedagogicamente para uma abertura do saber para além da pura teoria:

Na passagem em destaque de Grande Sertão: Veredas, é válido notar que dentre todos os membros da comunidade, apenas um, Riobaldo, era portador de um senso critico sensível e amplo, buscando não apenas a saída mais fácil, seguindo a vontade de vingança do povo, mas sim a justiça, ou o que mais próximo chegasse dela. Dentre todos, Riobaldo era o único que possuía um ensino básico, o que faz acreditar que o acesso a educação, mesmo que de qualidade mínima, interfere na visão do indivíduo perante a sua realidade e a do próximo, buscando soluções que satisfaçam ética e justiça de forma equilibrada.

Não há dúvida de que o episódio de "Grande Sertão: veredas" influenciou no apreender/aprender do conteúdo programático. O acesso à educação leva a uma superação da vingança privada pura e simples, leva à sofisticação no conceito de justiça - e tudo isso não foi conectado com base em conteúdos estanques apresentados de forma fria e distante. Os estudantes vivenciaram o drama dos personagens e partilharam de suas emoções e dos problemas de sua visão rude do mundo que os cercava. $\mathrm{O}$ grupo 3 da Turma $\mathrm{M}$ assim se manifestou:

Ainda assim, Zé Bebelo foi condenado a uma espécie de exílio, pelo simples fato de pertencer a um grupo inimigo daquele que o capturou (o grupo de Riobaldo). Tais questões demonstram que o "direito" se adequou à realidade do sertão marcada pela ausência de normas bem estruturadas, pela violência e pelo ódio entre grupos rivais. Mesmo que o direito ali aplicado não tenha se sobreposto de modo justo ou constitucional, que seria a melhor maneira de surgir e se adequar em qualquer sociedade, ele foi moldado de acordo com a realidade violenta, passional e desregrada do sertão.

O grupo 9 (Turma M) resume bem a ligação entre teoria e imaginação narrativa:

A cena do julgamento de Zé Bebelo, em Grande Sertão Veredas, trata da formação de uma instituição de direito, em pleno sertão, que consistiu na troca de armas por argumentação e do reconhecimento do réu como indivíduo. (...) Essa cena é de grande importância para entender o papel do direito no Brasil, (...). Mesmo não possuindo muito conhecimento sobre norma, estado de direito e afins, os sertanejos 
conseguiram montar uma instituição jurídica de modo a tratar o réu, Zé Bebelo, de forma mais digna.

O conteúdo "Direito e Estado Constitucional" também foi trabalhado a partir de um filme de ficção baseado em livro homônimo "Senhor das Moscas", cuja trama é a seguinte: um grupo de garotos acaba numa ilha deserta, tendo de estabelecer a convivência e a sobrevivência sem qualquer supervisão ou participação de adultos. Ao longo do filme, dois grupos se formam: um ligado aos personagens Ralph e Piggy, baseado em decisões colegiadas e direito de manifestação, e outro ligado a Jack, autoritário e baseado na violência. Na Wiki, os grupos tiveram de fazer a seguinte atividade: “Considerando o filme 'Senhor das Moscas' e a leitura obrigatória da semana, construam um texto coletivo analisando a Lei da Ficha Limpa e a sua relação com os princípios fundamentais da Constituição da República. Lembrem-se de verificar o artigo $5^{\circ}$ da Constituição e de estabelecer uma relação entre legalidade e democracia".

Na Turma N, o grupo 10 detectou a relação entre a peça de ficção e o conteúdo lecionado da seguinte forma:

Os que pensaram de maneira racional (Piggy e Ralph), tentaram de maneira não efetiva instituir uma espécie de estado de direito, com normas e regras que basicamente se mostraram ineficazes. Fundamentalmente porque o outro grupo detinha de força suficiente para disponibilizar recursos escassos na sociedade racional.

O grupo 2 da Turma A, fazendo a ligação do filme com a Lei da Ficha Limpa (que surgiu a partir de iniciativa popular), construiu assim seu texto:

No cenário retratado em "Senhor das moscas", tal reinvindicação seria muito mais difícil de ocorrer e ser atendida, pois não existe nenhum documento ou acordo que estabeleça a democracia como um pilar da sociedade, tal como faz a Constituição brasileira, o que torna o espaço mais propício ao surgimento de tiranos e à repressão daquilo que é melhor para o coletivo.

O mesmo tipo de abordagem também foi encontrado nos demais grupos. Os dados apresentam uma linha coerente, embora existam obviamente diferenças de estilo e capacidade de síntese: colaboração na redação da Wiki e ligação entre o conteúdo artístico com as questões jurídicas colocadas, desde que instigados pela pergunta do professor. Assim, por exemplo, quando a proposta da atividade não engloba a imaginação narrativa expressamente, não se pode detectar o uso explícito de tal capacidade. Isso se deu em duas aulas que, pela especificidade da questão proposta para a wiki, impossibilitou uma conexão explícita entre o 
filme de ficção e a atividade: a aula sobre "Repensando o normativo: o público e o privado" e “Relação jurídica: poderes, direitos e obrigações". Na primeira, a questão proposta foi:

\begin{tabular}{|c|}
\hline $\begin{array}{l}\text { Elaborem, colaborativamente, a partir das diretrizes da Constituição, uma lei para } \\
\text { regular algum tipo de atividade econômica, cultural ou social relevante nos dias de } \\
\text { hoje que não tenha ainda sido regulamentada (o primeiro que começar a wiki, tem o } \\
\text { privilégio da escolha da atividade a ser regulada). Para saber qual o tipo de lei e } \\
\text { como ela deve } \quad \text { ser } \quad \text { escrita, consultem } \\
\text { http://www4.planalto.gov.br/centrodeestudos/assuntos/manual-de-redacao-da- }\end{array}$ \\
\hline
\end{tabular}

Todavia, há de se reconhecer que a imaginação narrativa se expressa nesse contexto específico na forma como o estudante utiliza sua imaginação para produzir uma lei a qual possa dar conta de um problema social, econômico ou cultural. Requer-se do estudante uma capacidade de apreender os problemas contemporâneos e imaginativamente se colocar no papel de legislador e produzir um instrumento jurídico capaz de corrigir uma falha institucional.

Já na segunda, a seguinte atividade foi pedida dos estudantes:

Considerando a decisão judicial do TST em relação à dispensa por justa causa da orientadora da empresa "vigilantes do peso" em razão de ela se encontrar acima do peso (de acordo com a cláusula contratual que autoriza a dispensa por justa causa em casos de sobrepeso) em [...] elaborem uma nova decisão judicial em relação à cláusula contratual restritiva, levando em conta os princípios constitucionais constantes dos artigos $5^{\circ}, 6^{\circ}$ e $7^{\circ}$ da Constituição Brasileira.

Nessa segunda atividade, ao assistirem um seriado em que são relatados casos judiciais extraídos da realidade americana, sendo um deles referente à perda do emprego por excesso de peso da garçonete de um típico bar composto de modelos femininas e masculinos. Apresenta-se ao estudante um caso real extraído do Tribunal Superior do Trabalho, bem semelhante ao caso estadunidense e à obra de ficção, de sorte que o educando possa, imaginativamente, se colocar no lugar do juiz, um espaço privilegiado do contexto jurídico, e, assim, construir uma decisão judicial mais apropriada ao processo narrativo do seriado e ao contexto constitucional brasileiro.

Finalmente, o filme "Invasões bárbaras", também uma ficção, não foi acompanhado de nenhuma atividade dos alunos por ser visto na última aula. Com isso, não foi possível obter dados para analisar o uso da terceira capacidade elencada por Nussbaum. 


\section{CONCLUSÃO}

Os dados coletados e a análise qualitativa empreendida indicam que as inovações no método do ensino da disciplina "Instituições de Direito" da UFJF tem se mostrado eficazes no sentido de desenvolver as capacidades elencadas por Martha C. Nussbaum. Em relação à primeira capacidade, fica claro que a plataforma online com atividades de fóruns de debates e elaboração de textos colaborativos (wikis) evidenciam que o dar/cobrar argumentos está presente no dia-a-dia dos estudantes, até porque essas atividades tem frequência semanal. Os temas geralmente se conectam com questões polêmicas, o que também instiga a capacidade de argumentação dos educandos. Uma falha encontrada foi a pouca participação dos tutores no estímulo aos debates nos fóruns, que geralmente carecem de uma troca mais profícua de réplicas e tréplicas. Mas, de um modo geral, isso não impede que cada um se veja forçado a argumentar levando em conta as opiniões dos colegas de grupo, apesar de, ao analisar os dados, não se ter constatado isso com maior frequência e adequação à capacidade nussbaumiana.

No que concerne à segunda capacidade, como o conteúdo programático envolve autor que trabalha a teoria do reconhecimento (Axel Honneth), os estudantes se atentam para este tema e o relacionam com a matéria jurídica. Como se constata no decorrer do artigo, a própria escolha dos filmes dá a dimensão da abertura do programa da disciplina para as diferenças e para o outro distante (“distant other"). De fato, há oito países diferentes nas produções dos filmes, distribuídos em quatro continentes (Europa, África, América do Norte e América do 
Sul). Quanto aos filmes brasileiros, como já destacado, eles expõem os alunos a realidades periféricas ou polêmicas que os aproximam da temática do reconhecimento.

Finalmente, quanto à imaginação narrativa, que foi o objeto importante da presente pesquisa, verificou-se que o uso da ficção em filmes e episódios de seriados foi peça-chave do processo de ensino-aprendizagem. Os educandos, embora tivessem ocasionalmente dificuldades no estabelecimento da relação entre ficção e reconhecimento (no contexto jurídico), na maior parte de seus textos, souberam justamente cumprir esse intento, utilizando a imaginação narrativa. Houve mesmo um esforço de trazer as tramas fictícias para o centro dos textos colaborativos, a fim de estabelecer uma conexão entre o conteúdo teórico-jurídico e o cultural-fictício. A fria racionalidade do Direito, tantas vezes puramente dogmática, encontrou nos filmes uma abertura para as emoções como meio de aprendizado.

O presente artigo foi introduzido com uma crítica ao ensino jurídico e sua dominação pela força do dogmatismo e enciclopedismo. Seu final, todavia, não terá o mesmo tom pessimista. Ao contrário: a presente pesquisa demonstrou que há espaço para abordagens inovadoras que fogem aos esquemas rígidos da litania usual dos professores do Direito. O uso dos filmes de diferentes países e temáticas, a elaboração de textos de forma colaborativa em ambiente virtual, tudo isso vem sendo usado na disciplina "Instituições de Direito" da UFJF, com satisfatório retorno no aprendizado dos estudantes. $\mathrm{O}$ resultado da presente pesquisa, portanto, indica um caminho inovador para a educação jurídica, livre de um roteiro já cansado da mera repetição do mundo oficial.

\section{REFERÊNCIAS}


ABA-Approved Law Schools. Disponível em http://www.americanbar.org/groups/legal_education/resources/aba_approved_law_schools.ht ml>. Acesso em 05/09/2016.

ADEODATO, João Maurício. Advogado em Construção. In: Ensino Jurídico OAB: 170 anos de cursos jurídicos no Brasil. Brasília: OAB Conselho Federal, 1997.

BANKOWSKI, Zenon. Vivendo plenamente a Lei. Rio de Janeiro: Elsevier, 2008.

BASTOS, Aurélio Wander. O Ensino Jurídico no Brasil e as suas Personalidades Históricas: uma recuperação de seu passado para reconhecer seu futuro. In: Ensino Jurídico OAB: 170 anos de cursos jurídicos no Brasil. Brasília: OAB Conselho Federal, 1997.

COHAN, Peter. Does America need 202 law schools? Disponível em < http://www.forbes.com/sites/petercohan/2013/01/31/does-america-need-202-lawschools/\#26927e5b167b>. Acesso em 01/06/2016.

Constituição da República Federativa do Brasil de 1988. Disponível em < https://www.planalto.gov.br/ccivil_03/Constituicao/Constituicao.htm>. Acesso em $15 / 08 / 2016$.

DEL MAR, Maksymilian. Beyond text in legal education: art, ethics, and the Carnegie report. Loyola Law Review, vol. 56, p. 955-994, 2010. Disponível em $<$ https://www.copyright.com/ccc/basicSearch.do?\&operation=go\&searchType=0\&lastSearch $=$ simple $\&$ all $=$ on \& titleOrStdNo=0192-9720>. Acesso em 01/09/2016.

EPSTEIN, Lee. KING, Gary. The rules of inference. Disponível em <http://polmeth.wustl.edu/media/Paper/king02.pdf>. Acessado em 12/07/2016.

FONSECA JÚNIOR, W. C. Análise de conteúdo. In: DUARTE, J. BARROS, A. (Org.). Métodos e Técnicas de Pesquisa em Comunicação. São Paulo: Atlas, 2006, p. 280-304.

HONNETH, Axel. Luta por reconhecimento: a gramática moral dos conflitos sociais. São Paulo: Ed. 34, 2003.

IBGE - Instituto Brasileiro de Geografia e Estatística. PAS - Projeção da população do Brasil e das Unidades da Federação. Disponível em < http://www.ibge.gov.br/apps/populacao/projecao/>. Acesso em 06/09/2016.

MEC - Ministério da Educação. Instituições de Educação Superior e Cursos Cadastrados. Disponível em < http://emec.mec.gov.br/>. Acesso em 06/09/2016.

NUSSBAUM, Martha C. Cultivating humanity - A classical defense of reform in liberal education. Cambridge: Harvard University Press, 2003.

Poetic Justice. Boston: Beacon Press, 1995. 


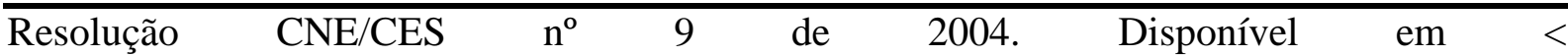

http://portal.mec.gov.br/cne/arquivos/pdf/rces09_04.pdf>. Acesso em 10/07/2016.

RORTY, Richard. Contingência, ironia e solidariedade. São Paulo: Martins Fontes, 2007.

UNGER, Roberto Mangabeira. $\quad$ Disponível em <http://bibliotecadigital.fgv.br/ojs/index.php/rda/article/viewFile/42553/41316>. Acessado em 27/05/2016.

UNITED STATES CENSUS BUREAU. U.S. and World Population Clock. Disponível em < http://www.census.gov/popclock/>. Acesso em 06/09/2016. 